\title{
A fraternidade como condição de possibilidade para o trato constitucionalmente adequado do refugiado: a tensão entre a integração e a segregação do outro no Brasil do século XXI
}

\author{
Fraternity as a condition of possibility for the constitutionally \\ adequate treatment of refugees: the tension between integration \\ and the segregation of the other in 21st century Brazil
}

\author{
Edson Vieira da Silva Filho ${ }^{1}$
}

Marina Helena Vieira da Silva ${ }^{2}$

\begin{abstract}
RESUMO
Considerando o processo de globalização pelo qual passa o mundo, e o aumento elevado no número de refugiados no Brasil nos últimos tempos devido às zonas de conflitos e crises locais que expulsam pessoas de suas terras natais, faz-se necessária a compreensão do refugiar-se enquanto única opção de alguns indivíduos vulneráveis. O presente trabalho partirá da análise do fenômeno refúgio e dos refugiados, passando pela discussão da tensão existente entre a integração por quem os recebe e a segregação praticada por alguns, gerando manifesta dificuldade no recebimento adequado do "outro" em um país de modernidade tardia, devido a ausência de compreensão adequada do tema e, ainda, considerando que o dividir na abundância é mais fácil do que partilhar na pobreza. $\mathrm{O}$ crescente número de refugiados em um país como o Brasil, onde as contradições sociais se mostram de modo pronunciado, levam à necessidade de uma compreensão que vá além dos dispositivos legais que regulam a matéria. A fraternidade será a ferramenta necessária para que seja analisada a tensão do acolhimento X expurgo, levando à compreensão adequada da necessidade do acolhimento por quem recebe os refugiados. Por fim, a partir do conceito de alteridade, e da concepção do "outro" para Bauman, serão discutidos os fatores que levam ao medo do estranho e consequente segregação frente ao complexo processo de construção hermenêutica em um país que possui pequenas ilhas de riqueza e grandes zonas de miséria, de forma que o partilhar se torna uma prática que demanda mais tolerância,inclusão e fraternidade.
\end{abstract}

\section{PALAVRAS-CHAVE:}

Refugiados, Globalização, Constitucionalismo.

\section{ABSTRACT}

Considering the globalization process the world is going through, and the high increase in the number of refugees in Brazil in recent times due to areas of conflict and local crises that expel

\footnotetext{
${ }^{1}$ Pós Doutor pela UNISINOS, Doutor em Direito pela UNESA na linha Direitos Fundamentais e Novos Direitos, Mestre pela Universidade Federal do Paraná, Mestre pela Universidade São Francisco, Graduado em Direito pela PUC Belos Horizonte - MG. Delegado de Polícia Classe Geral, aposentado; Professor Adjunto da Faculdade de Direito do Sul de Minas; Professor do PPGD da FDSM. Vice Presidente da Fundação Sul Mineira de Ensino.

${ }^{2}$ Mestranda em Direito, com área de concentração em Constitucionalismo e Democracia, na linha de pesquisa Relações Sociais e Democracia pela Faculdade de Direito do Sul de Minas (FDSM). Pós Graduada pela Escola Paulista de Direito (EPD) em Direito Civil e Processual Civil. Graduada pela Faculdade de Direito do Sul de Minas (FDSM). Advogada.
} 
people from their homelands, it is necessary to understand the refugee as the only option for some vulnerable individuals. The present work will start from the analysis of the phenomenon of refuge and refugees, going through the discussion of the existing tension between the integration by those who receive them and the segregation practiced by some, generating manifest difficulty in the adequate reception of the "other" in a country of late modernity, due to the absence of adequate understanding of the subject, and also considering that dividing in abundance is easier than sharing in poverty. The growing number of refugees in a country like Brazil, where social contradictions are pronounced, leads to the need for an understanding that goes beyond the legal provisions that regulate the matter. Fraternity will be the necessary tool to analyze the tension of reception X expurgo, leading to a proper understanding of the need of reception by those who receive refugees. Finally, from the concept of otherness, and the conception of the "other" for Bauman, the factors that lead to the fear of the strange and consequent segregation in face of the complex process of hermeneutic construction in a country that has small islands of wealth and large areas of misery will be discussed, so that sharing becomes a practice that demands more tolerance, inclusion and fraternity.

\section{KEYWORDS:}

Refugees, Globalization, Constitutionalism.

\section{INTRODUÇÃO}

A questão do refúgio tem se tornado um fenômeno cada vez mais presente na vida dos brasileiros, sendo possível constar, principalmente a partir da mídia, que nos últimos tempos inúmeras famílias deixam seus países de origem buscando acolhimento em locais muitas vezes distantes, com culturas distintas, objetivando proteção em face de violências sofridas em seus países de origem.

Um dos problemas existentes na migração involuntária, mais especificamente no refúgio, é que o ato de pedir o refúgio e de acolher-se refugiados, é repleto de contradições que passam por conceitos ligados ao senso comum e à dogmática jurídica moderna, chegando ao constitucionalismo contemporâneo como novidade, que, por sua vez, devido ao fato de ser mal compreendida, acaba por ser extremamente mal trabalhada e aplicada na prática, de forma que o refúgio/refugiado acabam por ser concebidos como sinônimo de ameaça.

Neste contexto, a partir do pensamento de Zigmunt Bauman, será desenvolvida a definição do outro e delimitadas quais as razões para que, em um processo de globalização pelo 
mundo, ainda haja o medo e a hostilidade para com o outro, em especial o refugiado, ressaltando que o compreender os refugiados e o instituto refúgio é um processo complexo que passa necessariamente pelo compreender o outro.

Se é possível perceber, a partir de perspectivas tradicionais, o refugiado como um estranho e consequentemente como ameaça, visto que partilha o nosso pão (metaforicamente falando), é fácil compreendê- $\mathrm{lo}^{3}$ a partir dos processos de objetificação e de defesa próprios dos conceitos tradicionais de soberania. Assim, a hostilidade destinada ao estranho ganha proporções vultuosas quando aquele que é diferente, por de fato sê- $1 \mathrm{o}^{4}$, passa a ser considerado como conturbador da ordem e causador de pânico, justamente por ser tido como ameaça.

Por outro lado, a compreensão do outro deve ultrapassar as perspectivas tradicionais existentes, e, a partir do conceito de alteridade trabalhado por Emmanuel Lévinas, o outro deve ser visto sem qualquer forma de exclusão ou rejeição, a partir de uma ideia de colocação da pessoa na totalidade, se situando com relação aos demais, concebendo a realidade exterior à individual ${ }^{5}$.

Conceber a perspectiva do outro como hostil e como quem quer partilhar sem ter participado do construir, e, a partir dessa perspectiva, construir com o outro um vínculo de rejeição e de expurgo, é algo que se dissocia de toda a compreensão moderna do indivíduo, e, a inclusão, a partilha, o acolher, passa pelo compreender a subjetividade do outro em uma perspectiva includente e fraternal.

É claro que, para compreendermos o refúgio, precisamos de referências acerca do “outro" enquanto sujeito/indivíduo e do sentido atribuído a ele, visto que, ainda modernos, teremos dificuldades em acolher e facilidade em exilar, sendo que os processos eugênicos não nos causam tanto asco quando destinados aos diferentes.

\footnotetext{
${ }^{3}$ Compreender, para Hannah Arendt, significa encarar a realidade sem preconceitos e com atenção, e resistir a ela, qualquer que seja, suportando os fardos que os acontecimentos colocam sem negar sua existência. ARENDT, Hannah. Origens do totalitarismo. Tradução de Roberto Raposo. São Paulo: Companhia das Letras, 2012. p. 21. ${ }^{4} \mathrm{~A}$ diferençapode se apresentar em diversos aspectos, considerando que, além de vir de terras distantes, o refugiado possui uma cultura diferente, professando cultos estranhos aos que o recebem, e cultivando laços relacionais difíceis de serem compreendidos.

${ }^{5}$ LÉVINAS, Emmanuel. Entre nós: ensaios sobre a alteridade. Tradução de Pergentino Pivatto...[et al], 5.ed. Petrópolis, RJ: Vozes, 2010.p. 37
} 
Neste sentido, o pensamento de Bauman possui relevância para o presente trabalho no que se refere aos estudos acerca da globalização e seus reflexos na vida dos indivíduos, sendo necessário para a compreensão do outro como sujeito, que, por sua vez, deve ser acolhido e não discriminado.

Como se não bastasse a ideia de partilhar em estado de abundância, é considerada quase um ato de filantropia a caridade daqueles que muito têm, distribuindo os seus restos para os miseráveis, e isso é algo que não se apresenta como um problema, no entanto, quando nos referimos a um país de modernidade tardia, como o Brasil, onde nos deparamos com o dividir (n)a miséria, são gerados questionamentos com relação ao pensamento fraterno e a consequente ideia de partilha, e é aqui que surge a necessidade da construção de um sentido ao que se refugia, tendo como base os preceitos constitucionais que garantem, por diversos meios, a igualdade e os direitos dos estrangeiros, e, consequentemente, dos refugiados.

Finalmente, a construção de sentido constitucional deve se dar a partir do mundo concreto, visto que a compreensão vem da práxis e o outro se forma a partir do tempo ${ }^{6}$, sendo que justamente nesse tempo que precisamos inserir o refugiado para que ele receba o acolhimento adequado, levando em conta sua situação de vulnerabilidade.

A análise do refúgio apartada da concretude levará a visões distorcidas e equivocadas, sendo natural a tendência à discriminação da pessoa que, a uma primeira impressão, causa estranheza e medo por ser diferente em aspectos pessoais e culturais, de forma que, se torna imprescindível a compreensão do "outro" como sujeito.

Parte-se, assim, da compreensão histórica do refúgio para inserir-se uma perspectiva plural e fraterna, para que, ao final seja possível desenhar uma perspectiva de adequação constitucional à opção pelo acolhimento pautado pelo ideal de fraternidade e pela consequente quebra da tensão existente entre a diferença e a igualdade, a partir de uma análise da relação expurgo x acolhimento, e da proteção constitucional conferida ao refugiado em um país de modernidade tardia, que é o Brasil.

Assim, o refugiado, compreendido no seu tempo e espaço, não só pode como deve ter direito a uma resposta constitucionalmente adequada, resposta que só pode ser construída a

\footnotetext{
${ }^{6}$ No sentido Heideggeriano.
} 
partir de compromisso civilizatório, firmado por nós (como quem os recebe) para nós mesmos, para que, consequentemente, o que é devido a ele possa enfim lhe ser dado.

\section{A COMPREENSÃO DO FENÔMENO REFÚGIO}

Incorporada pela Declaração de Cartagena de $1984^{7}$, que estabeleceu importantes critérios para a análise do refúgio ${ }^{8}$, a lei no 9.474, de 22 de julho de 1997, em seu artigo $1^{\circ}$, determina as hipóteses em que estrangeiros poderão ser reconhecidos como refugiados no Brasil $^{9}$.

A referida lei expõe, ainda, em seus 49 artigos, os mecanismos para a implementação da Convenção Relativa ao Estatuto dos Refugiados, de 1951, no Brasil ${ }^{10}$, sendo determinadas, ainda, outras providências referentes à questão "refúgio". As questões abordadas são de extrema relevância à compreensão da forma pela qual se concretiza o procedimento de refúgio no Brasil $^{11}$, entretanto, não são suficientes para tratar dos problemas que envolvem o procedimento

\footnotetext{
${ }^{7}$ Declaração de Cartagena de 1984. Disponível em:

https://www.acnur.org/fileadmin/Documentos/portugues/BD_Legal/Instrumentos_Internacionais/Declaracao_de _Cartagena.pdf Acesso em: 15 de junho de 2019.

${ }^{8}$ Como a conceituação do refugiado com base em direitos fundamentais da pessoa humana, além de uma relação direta com o direito internacional humanitário. CARNERIO, Wellington Pereira. A declaração de Cartagena de 1984 e os desafios da proteção internacional dos refugiados, 20 anos depois. In: Org.: DA SILVA, César Augusto. Direitos Humanos e Refugiados. Dourados: Ed. UFGD, 2012. p. 19.

${ }^{9}$ Segundo o artigo $1^{\circ}$ da Lei $n^{\circ} 9.474$, será reconhecido como refugiado todo indivíduo que: I - devido a fundados temores de perseguição por motivos de raça, religião, nacionalidade, grupo social ou opiniões políticas encontrese fora de seu país de nacionalidade e não possa ou não queira acolher-se à proteção de tal país; II - não tendo nacionalidade e estando fora do país onde antes teve sua residência habitual, não possa ou não queira regressar a ele, em função das circunstâncias descritas no inciso anterior; III - devido a grave e generalizada violação de direitos humanos, é obrigado a deixar seu país de nacionalidade para buscar refúgio em outro país.

${ }^{10}$ O objetivo da referida convenção, adotada em 28 de julho de 1951, foi a resolução da situação dos refugiados na Europa após a Segunda Guerra Mundial. Estabelece a definição de refugiado e esclarece os direitos e deveres que os cercam. Disponível em:

https://www.acnur.org/portugues/convencao-de-1951/e

https://www.acnur.org/fileadmin/Documentos/portugues/BDL/Convencao_relativa_ao_Estatuto_dos_Refugiado s.pdf Acesso em: 15 de junho de 2019

${ }^{11}$ Segundo o relatório "Refúgio em Números", divulgado pelo CONARE, o Brasil reconheceu até o final de 2017, um total de 10.145 refugiados. Disponível em:

https://www.acnur.org/portugues/wp-content/uploads/2018/04/refugio-em-numeros_1104.pdf
} 
de refúgio, e, principalmente, a ausência de compreensão do "outro" como um ser humano, livre, detentor de direitos, e, principalmente, vulnerável, aberto ${ }^{12}$.

As primeiras notícias do tratamento do refúgio como questão juridicamente independente não ocorreram há muito tempo, sendo que a necessidade da existência de uma forma específica para o acolhimento de massas deslocadas, com reconhecimento jurídico, se deu no início do século XX, sendo, que, anteriormente, as questões existentes eram tratadas de acordo com as regras do asilo ou até mesmo de extradição ${ }^{13}$.

Dessa forma, primeiramente, foi criada a Organização Internacional dos Refugiados, em 1947, posteriormente, a ACNUR ${ }^{14}$, em 1950, e, ainda, a Convenção sobre o Estatuto dos Refugiados de 1951, aderida pelo Brasil em 1952 e incluída no ordenamento jurídico em $1961^{15}$.

Em um processo de globalização pelo mundo, em que há a pretensão de expansão para além das fronteiras territoriais dos Estados ${ }^{16}$, nos deparamos com uma dinâmica social que vai além de um direito constituído a partir de tratados ou costumes, sendo insuficiente, ainda, a regulação a partir de um ordenamento fixo, tornando necessária, segundo Hespanha, uma maleabilidade normativa.

Mesmo sendo o Brasil um país com destaque no que se refere à proteção dos refugiados ${ }^{17}$, visto que, além de ser o primeiro país do Cone Sul a ratificar a Convenção relativa ao Estatuto dos Refugiados de 1951 , no ano de $1960^{18}$, tem a sua legislação sobre o tema utilizada como modelo em diversos países ${ }^{19}$, o cenário atual demonstra a dificuldade no suporte

\footnotetext{
${ }^{12}$ Para Lévinas, a aberturaé a vulnerabilidade de uma pele exposta à ferida e ofensa para além do que pode ser exposto à compreensão. LÉVINAS, Emmanuel. Humanismo do outro homem. 4. ed. Petrópolis, RJ: Vozes, 2012. p. 99.

${ }^{13}$ NASCIMENTO, Luiz Sales do. A cidadania dos refugiados no Brasil. 2. Ed. São Paulo : Editora Verbatim, 2014.p. 33

${ }^{14} \mathrm{O}$ Alto Comissariado das Nações Unidas atua como um órgão subsidiário da ONU e trata diretamente das questões ligadas aos refugiados e aos apátridas. PEREIRA, Gustavo de Lima. Direitos humanos e migrações forçadas: introdução ao direito migratório e ao direito dos refugiados no Brasil e no mundo. Porto Alegre: EDIPUCRS, 2019.p. 39.

${ }^{15}$ NASCIMENTO, Luiz Sales do. A cidadania dos refugiados no Brasil. 2. Ed. São Paulo : Editora Verbatim, 2014. p. $34 / 38$

${ }^{16}$ HESPANHA, António Manuel. O caleidoscópio do direito: o direito e a justiça nos dias e no mundo de hoje. $2^{\text {a }}$ ed. Coimbra: Edições Almedina, 2014. p. 432.

17 PEREIRA, Gustavo de Lima. Direitos humanos e migrações forçadas: introdução ao direito migratório e ao direito dos refugiados no Brasil e no mundo. Porto Alegre: EDIPUCRS, 2019. p. 63.

${ }^{18}$ Informação extraída do site da ACNUR. Disponível em: https://www.acnur.org/portugues/acnur-no-brasil/

${ }_{19}$ PEREIRA, Gustavo de Lima. Direitos humanos e migrações forçadas: introdução ao direito migratório e ao direito dos refugiados no Brasil e no mundo. Porto Alegre: EDIPUCRS, 2019. p. 63.
} 
aos refugiados, que, muitas vezes concebidos como estranhos, gerando medo e insegurança, são tratados de forma inadequada no país que os recebe, sendo, muitas vezes estigmatizados ${ }^{20}$, e, como consequência dessa estigmatização, há a exclusão da relação social e a ausência de percepção de qualidades dos estigmatizados, transmitindo uma ideia de inferioridade e de perigo, sendo tratados como estranhos que não seriam suficientemente bons para participar de algum grupo, considerados outsiders ${ }^{21}$.

Embora haja grande relevância na existência de lei específica para regulação do refúgio, como de fato há no Brasil, visto que estabelece o procedimento e demais regulamentações objetivas sobre a matéria, não há qualquer dispositivo que trate especificamente do ato de recepcionar o outro, sendo necessário estabelecer uma compreensão do ato de dar refúgio, e consequentemente de receber o refugiado, não como hospedes indesejados, mas sim por um desdobramento contemporâneo da fraternidade ${ }^{22}$, concebendo-os no vértice da compreensão não mais moderna ${ }^{23}$, liberal individual, burguesa, mas sim de uma sociedade contemporânea, social, plural e democrática.

Não é suficiente, portanto, a observância dos conceitos e definições estabelecidos em lei acerca do refúgio, ressaltando que atualmente, a maioria das pe ssoas são tão somente objeto dos discursos de direitos humanos, não sendo tocadas pelos seus efeitos ${ }^{24}$, fazendo-se necessária a reprodução do que se compreende por sujeito, ou seja, quem é o "outro ${ }^{25}$ capaz de causar

\footnotetext{
${ }^{20}$ O estigma pode ser conceituadocomo uma marca que possui significado depreciativo, não necessariamente uma marca física, mas também de imagem social que é feita de determinadas pessoas para que se possa con trola-los. BACILA, Carlos Roberto. Estigmas: um estudo sobre os preconceitos. Rio de Janeiro: Editora Lumen Juris: 2005. p 24/25.

${ }^{21}$ Ibidem. p. 28.

${ }^{22}$ Parafraseando Zigmunt Bauman, a fraternidade é um tema que resume alguns dilemas, tarefas a serem realizadas na infinitude, e se caracterizam como o símbolo de tentar alcançar o impossível: diferentes, mas os mesmos; separados, mas inseparáveis; independentes, mas unidos. BAUMAN, Zigmunt. Identidade: entrevista a Benedetto Vecchi. Tradução de Carlos Alberto Medeiros. Rio de Janeiro:Zahar, 2005, p. 16

${ }^{23}$ A modernidade sempre buscou exercer o maior controle possível sobre o corpo e a alma dos seres humanos, sem que para tanto fosse necessário o extermínio físico. BAUMAN, Zigmunt; DONSKIS, Leonidas. Cegueira moral: a perda da sensibilidade na modernidade líquida. Tradução: Carlos Alberto Medeiros. 1.ed. Rio de Janeiro: Zahar, 2014. p. 40.

${ }^{24}$ SANTOS, Boaventura de Souza. CHAUI, Marilena. Direitos humanos, democracia e desenvolvimento. São Paulo: Cortez, 2013.p. 42

${ }^{25} \mathrm{Na}$ modernidade, os indivíduos eram identificados como iguais, sendo que na contemporaneidade passama ser compreendidos como diferentes. A igualdade é um construído, elaborado de forma convencional por meio de decisões que garantem a todos os mesmos direitos, enquanto a diferenciação, por sua vez, demonstra cada indivíduo com sua especificidade. LAFER, Celso. A reconstrução dos direitos humanos: um diálogo com o pensamento de Hannah Arendt. São Paulo: Companhia das Letras, 1988. p. 150/151
} 
verdadeiro pânico moral ${ }^{26}$ e qual a razão para uma ansiedade e medo no ato de recepção do estranho, que é, por sua vez, indesejado.

A partir, portanto, de uma análise principiológica, considerando os princípios não de forma genérica, como nos princípios gerais do direito, mas sim como sendo decorrentes de valores concretos, tendo como função justamente, por muitas vezes, agirem antes mesmo da existência de leis específicas no sentido que estes determinam ${ }^{27}$.

Deve ser analisado o evento refúgio em uma perspectiva de paridade e inclusão, e não de diferença. A leitura do "estranho acolhido" deve transcender os critérios convencionais de um recebimento de visitantes em seu lar, reproduzindo o que se compreende como sujeito, o conceito do outro e, por fim, reconhecendo a subjetividade (status de sujeito).

\section{ESCORÇO HISTÓRICO DA COMPREENSÃO FRATERNA DO “OUTRO”}

É importante, neste momento, estabelecer um recorte temporal para que seja tratado o reconhecimento dos direitos humanos na história, e, também, da fraternidade, sendo que, partindo do paradigma da modernidade, será realizada uma breve recapitulação dos principais pontos históricos necessários para o tema e para o entendimento acerca da forma que se dão as relações intersubjetivas que envolvem uma situação de refúgio.

Após o período medieval, com o desgaste do feudalismo, surge um novo modelo econômico e social, a partir de uma nova visão de mundo desenvolvida pela moderna cultura europeia ocidental ${ }^{28}$, passando o direito a ser institucionalizado como vontade do Estado, e concebido como reprodutor da vontade geral, sendo que, por não ser encontrada uma classe

\footnotetext{
${ }^{26}$ Para Bauman, a crise migratória se apresenta, atualmente, como causadora de um pânico moral na população, que é o sentimento de medo e ameaça sentido por um grande número de pessoas. BAUMAN, Zigmunt. Estranhos à nossa porta. Tradução de Carlos Alberto Medeiros. 1. ed. Rio de Janeiro: Zahar, 2017. p. 8

${ }^{27}$ CUNHA, Paulo Ferreira da. Repensando as fontes do Direito na sociedade da informação. Revista Opinião Jurídica, Fortaleza, v. 14, n. 19, p. 253-280, jan./jun. 2016.p. 267.

28 SILVA FILHO, Edson Vieira; KALLÁS FILHO, Elias. Nós modernos: a crise de efetividade do constitucionalismo contemporâneo à brasileira. In: SIMIONI, Rafael Lazzarotto (org.). Constitucionalismo e democracia 2017: reflexões do programa de pós-graduação em direito da FDSM. São Paulo: Editora Max Limonad, 2017.p.92/93
} 
capaz de se identificar com o governo, foi desenvolvido o Estado-nação ${ }^{29}$. Neste momento o indivíduo começa a ganhar expectativas ${ }^{30}$, sob a promessa de liberdade, igualdade, fraternidade, e segurança, acreditando, por sua vez, que essas irão se consolidar.

O ato migratório, incluindo o refúgio, objeto específico do presente estudo, deve ser visto como um direito humano, e não apenas como uma expectativa de direito ${ }^{31}$, e, de acordo com a compreensão moderna dos direitos humanos, três acontecimentos marcantes que ocorrem a partir do século XVII são importantes para o seu desenvolvimento: a revolução inglesa ${ }^{32}$, a revolução americana ${ }^{33}$ e a revolução francesa, sendo justamente os ideais iluministas de "Liberdade, Igualdade e Fraternidade" ${ }^{34}$, pregados na Revolução Francesa e constantes inclusive no preambulo da atual Constituição da República Federativa do Brasil ${ }^{35}$, que, segundo Kant, demonstraram a tendência para o pensamento livre e para a liberdade do modo de sentir do povo, refletindo, ainda, no tratamento do homem pelo governo com dignidade:

O Iluminismo é a saída do homem de sua menoridade de que ele próprioé culpado. A menoridade é a incapacidade de se servir do entendimento sem a orientação de outrem. Tal menoridade é por culpa própria se a sua causa não reside na falta de entendimento, mas na falta de decisão e de coragem em se servir de si mesmo sem a orientação de outrem. Sapere aude! Tem a coragem de te servires do teu próprio en tendimento! Eis a palavra de ordem do Iluminismo. ${ }^{36}$

${ }^{29}$ ARENDT, Hannah. Origens do totalitarismo. Tradução de Roberto Raposo. São Paulo: Companhia das Letras, 2012.p. 43.

${ }^{30}$ Para Hannah Arendt, o momento de expectativas é como a calma que sobrevém quando não há mais esperanças. ARENDT, Hannah. Origens do totalitarismo. Tradução de Roberto Raposo. São Paulo: Companhia das Letras, 2012.p. 11.

31 PEREIRA, Gustavo de Lima. Direitos humanos e migrações forçadas: introdução ao direito migratório e ao direito dos refugiados no Brasil e no mundo. Porto Alegre: EDIPUCRS, 2019.p. 22.

32 A partir da revolução inglesa, foi elaborada a Declaração dos Direitos de 1688, que, dentre outras coisas, reconhece a ilegalidade de que o Rei suspendesse leis ou deixasse de cumpri-las. LEAL, Rogério Gesta. Direitos humanos no Brasil: desafios à democracia. Porto Alegre: Livraria do Advogado, Santa Cruz do Sul, 1997. p. 31.

33 A Revolução Americana, por sua vez, foi marcada pela Convenção de Virgínia de 1776, que pode ser considerada como a primeira declaração de direitos moderna, traz em seu corpo a ideia de que todos os homens são livres e independentes, com fundamento em algumas premissas iluministas. LEAL, Rogério Gesta. Direitos humanos no Brasil: desafios à democracia. Porto Alegre: Livraria do Advogado, Santa Cruz do Sul, 1997.p. 32 ${ }^{34}$ SARLET, Ingo Wolfgang. A eficácia dos Direitos Fundamentais: uma teoria geral dos direitos fundamentais na perspectiva constitucional. 11. ed. rev. atual. Porto Alegre: Livraria do Advogado Editora, 2012 p. 38.

35 Preâmbulo: "Nós, representantes do povo brasileiro, reunidos em Assembléia Nacional Constituinte para instituir um Estado Democrático, destinado a assegurar o exercício dos direitos sociais e individuais, a liberdade, a segurança, o bem-estar, o desenvolvimento, a igualdade e a justiça como valores supremos de uma sociedade fraterna, pluralista e sem preconceitos, fundada na harmonia social e comprometida, na ordem interna e internacional, com a solução pacífica das controvérsias, promulgamos, sob a proteção de Deus, a seguinte CONSTITUIÇÃO DA REPÚBLICA FEDERATIVA DO BRASIL.” Disponível em:

http://www.planalto.gov.br/ccivil_03/constituicao/constituicaocompilado.htm Acesso em: 12 de agosto de 2019.

${ }^{36}$ KANT, Immanuel. A paz perpétua e outros opúsculos. Tradução de Artur Morilo. Edições 70: Lisboa, Portugal, s.d..p. 11. 
Partindo dos princípios iluministas, portanto, o homem passa a ter consciência de seu papel histórico, deixando para trás a limitação do acompanhamento da vida a partir de uma simples reflexão e adotando uma espécie de espontaneidade que origina do pensamento, dotado do poder de provocação, fugindo de uma forma rígida de disciplina ${ }^{37}$.

Foi justamente a Revolução Francesa, que teve seu marco principal em $1789^{38}$, com a tomada da bastilha, que trouxe a consequência da supressão dos direitos feudais e a Declaração dos Direitos do Homem e do Cidadão, importante referencial da universalidade dos direitos tanto individuais quanto coletivos das pessoas.

Ocorre que, atualmente, nos deparamos com um modelo de sociedade um que assume uma identidade includente (em construção), e que aos poucos deixa de ser liberal, individual e burguesa, para demonstrar traços de um modelo social plural e democrático, onde pessoas diferentes passam a poder conceber as mesmas coisas a partir de perspectivas diferentes, inexistindo uma racionalidade única que comanda os indivíduos, como se pretendia na modernidade.

Atualmente, a definição dos direitos humanos está mais ligada aos que eles não são do que de fato são ${ }^{39}$, sendo que, está longe do senso comum e de posicionamentos violentos e preconceituosos, como de que os direitos humanos se referem a conceitos retóricos e que servem tão somente às minorias, por exemplo. São, na realidade, direitos que acabam por se relacionar aos que buscam um mundo com menor violência e atingem a todos que a qualquer momento podem ter os seus direitos humanos violados ${ }^{40}$.

Deve-se ressaltar, ainda, a necessidade de compreendera situação do mundo global, sendo que as organizações humanitárias e relacionadas aos direitos humanos também contribuem para a contínua produção de normas internacionais, inexistindo uma limitação aos valores exclusivamente referentes ao mercado internacional, de forma a proporcionar normas mais efetivas. É justamente com este direito global que há a redução do protagonismo do poder

\footnotetext{
37 CASSIRER, Ernst. A filosofia do iluminismo. Tradução de Álvaro Cabral. Campinas, DP: Editora da UNICAMP, 1992.p. 11

${ }^{38}$ LEAL, Rogério Gesta. Direitos humanos no Brasil: desafios à democracia. Porto Alegre: Livraria do Advogado, Santa Cruz do Sul, 1997.p. 33

${ }^{39}$ PEREIRA, Gustavo de Lima. Direitos humanos e migrações forçadas: introdução ao direito migratório e ao direito dos refugiados no Brasil e no mundo. Porto Alegre: EDIPUCRS, 2019. p. 19/20.

${ }^{40}$ Ibidem. p. 21.
} 
estatal obtido com a Revolução Francesa ${ }^{41}$, decorrente de diversos fatores, como por exemplo, a lentidão e alienação do legislador com relação ao que ocorre na prática.

Neste contexto, em um mundo que passa por um processo de globalização, com indivíduos que, cada vez mais, reconhecem a subjetividade e a necessidade de efetivação dos direitos humanos, é importante mencionar a Lei $13.445 / 17^{42}$, que é também conhecida como nova Lei de Migração, que traz algumas alterações que apresentam, cada vez mais, a solidariedade e fraternidade presentes com relação ao refúgio, como por exemplo ${ }^{43}$, com a alteração da expressão “estrangeiro" por "migrante”, a utilização da expressão "direitos humanos" por diversas vezes, a ênfase na condição de igualdade dos migrantes e a previsão de acolhida humanitária e de reunião familiar ${ }^{44}$.

Os direitos de fraternidade ou solidariedade, também denominados direitos da terceira dimensão, exercem função importante neste contexto, sendo aqueles que se destinam não a um indivíduo único, mas sim a um determinado grupo humano ${ }^{45}$, podendo ser caracterizados como direitos de titularidade difusa e necessitando, ainda, de esforços em escala mundial para sua concretização.

Assim, a compreensão do refúgio/refugiado deve ultrapassar os preconceitos existentes e atingir uma perspectiva fraterna, que entenda o outro que pede abrigo em seu país não como uma ameaça, mas sim como um semelhante, que merece ser acolhido e amparado pela sua situação de vulnerabilidade e fragilidade por ser obrigado a se retirar de seu país de origem.

\footnotetext{
${ }^{41}$ HESPANHA, António Manuel. O caleidoscópio do direito: o direito e a justiça nos dias e no mundo de hoje. $2^{\mathrm{a}}$ ed. Coimbra: Edições Almedina, 2014. p. 437.

$42 \mathrm{O}$ texto decorre do Substitutivo da Câmara dos Deputados n ${ }^{\circ}$ 7, de 2016, ao Projeto de Lei do Senado $n^{\circ} 288$, de 2013, com iniciativa do Senador Aloysio Nunes Ferreira. Disponível em: https://www25.senado.leg.br/web/atividade/materias/-/materia/127792 Acesso em: 17 de agosto de 2019.

${ }^{43}$ PEREIRA, Gustavo de Lima. Direitos humanos e migrações forçadas: introdução ao direito migratório e ao direito dos refugiados no Brasil e no mundo. Porto Alegre: EDIPUCRS, 2019. p.77/79

${ }^{44} \mathrm{O}$ visto humanitário trata da possibilidade de que o apátrida ou nacional de qualquer país em graves situações elencadas na Lei de Migrações, e a reunião familiar trata da previsão do visto para o cônjuge ou companheiro do imigrante, aos filhos e demais familiares até segundo grau. PEREIRA, Gustavo de Lima. Direitos humanos e migrações forçadas: introdução ao direito migratório e ao direito dos refugiados no Brasil e no mu ndo. Porto Alegre: EDIPUCRS, 2019.p. 84/85.

${ }^{45}$ SARLET, Ingo Wolfgang. A eficácia dos Direitos Fundamentais: uma teoria geral dos direitos fundamentais na perspectiva constitucional. 11. ed. rev. atual. Porto Alegre: Livraria do Advogado Editora, 2012 p. 38
} 


\section{ANÁLISE DO REFÚGIO COMO DESDOBRAMENTO DA FRATERNIDADE}

É possível observar, no primeiro artigo da Declaração Universal dos Direitos Humanos de $1948^{46}$, a previsão acerca do espírito de fraternidade, que pode ser traduzido pela necessidade do sentimento para se viver, o resgate da sensibilidade das pessoas. Nesse sentido, o refugiado, antes de ser recebido com igualdade e liberdade, que também são imprescindíveis, deve ser recepcionado com fraternidade pelo próximo, sendo oferecida, de forma solidária e fraterna a proteção e o acolhimento que tanto buscam, para se seja possível o exercício dos demais direitos que lhes cabem, principalmente de liberdade e igualdade.

Será adotada como necessária, portanto, a perspectiva fraterna para a compreensão do refúgio/refugiado não como estranho, mas sim como outro que deve ser acolhido devido à sua condição de vulnerabilidade e de cidadão, podendo tanto ter direitos como exercer o direito a tê- $\operatorname{los}^{47}$.

Partindo do princípio de que a estigmatização é uma forma de negação do direito por meio da objetificação do outro e da retirada de sua condição de pessoa, tem-se que a negação dos estigmas pode ser vista como forma de reafirmação dos direitos ${ }^{48}$, entretanto, no que tange à questão dos refugiados, a existência de normas constitucionais prevendo a sua proteção e a determinação de impossibilidade de qualquer prática discriminatória não é suficiente para que haja uma recepção adequada àqueles que batem às portas de outros países.

A fim de que seja realizada uma adequada compreensão do refúgio/refugiado, deve-se partir da ideia de que, sem uma análise fraterna dos envolvidos no fenômeno, não será possível interpretar o que de fato ele é, e, sem que haja uma interpretação correta, consequentemente não será possível realizar uma leitura constitucionalmente adequada.

\footnotetext{
${ }^{46}$ Artigo I - Todos os seres humanos nascem livres e iguais em dignidade e direitos. São dotados de razão e consciência e devem agir em relação uns aos outros com espírito de fraternidade. Disponível em: https://nacoesunidas.org/wp-content/uploads/2018/10/DUDH.pdf Acesso em: 12 de agosto de 2019.

${ }^{47}$ NASCIMENTO, Luiz Sales do. A cidadania dos refugiados no Brasil. 2. Ed. São Paulo : Editora Verbatim, 2014.p. 51

${ }^{48}$ BACILA, Carlos Roberto. Estigmas: um estudo sobre os preconceitos. Rio de Janeiro: Editora Lumen Juris: 2005.p. 185.
} 
Tal postura deve ser adotada principalmente com a finalidade de preservação do direito à dignidade, não sendo uma faculdade, mas sim uma obrigação reconhecer e tutelar a dignidade de todos os indivíduos, respeitando e buscando a preservação de tal direito a todos, inclusive aos menos privilegiados, que se encontram em condição de vulnerabilidade em decorrência de casos históricos concretos que acarretaram reflexos na vida das pessoas ${ }^{49}$.

Tal leitura constitucionalmente adequada deve levar em conta, ainda, o processo de globalização, visto por Bauman como um processo de "grande transformação" que gerou reflexos tanto nas estruturas estatais, nas condições de trabalho, e relações entre os Estados, modificando, dentre outros aspectos, a subjetividade coletiva e as relações estabelecidas entre o eu e o outro ${ }^{50}$.

Nesse sentido, primeiramente deve-se compreender as igualdades, as diferenças, a alteridade e o medo a partir de tradições (em um sentido de horizontes gadamerianos) sobre as quais o Brasil se funda, para que, posteriormente, sejam regrados comportamentos e delimitadas as formas adequadas de hospitalidade do refugiado através de uma integração globalizante, objetivando afastar o perigo de perda do conhecimento acerca dos sofrimentos alheios e da própria sensibilidade com relação ao outro ${ }^{51}$.

Para a se compreenda o refúgio e a posição dos refugiados no mundo, faz-se necessário, entender, primeiramente, que a concepção plural de indivíduo que rompe com os dualismos modernos, é a que melhor se adequa aos ideias civilizacionais do Brasil contemporâneo, sendo necessário o convívio e a partilha, conforme ensina A. Castanheira Neves:

O mundo é um e os homens nele são muitos. Esta condição básica e decisiva, não obstante de um elementar truísmo, e não menos irredutível, pela qual a pluralidade dos homens se depara na unicidade do mundo, faz decerto com que aos homens, a comungarem o mesmo mundo, se imponha a necessidade tanto de nele conviverem como de o partilharem. ${ }^{52}$

\footnotetext{
${ }^{49}$ RESTA, Eligio; JABORANDY, Clara Cardoso Machado; MARTINI, Sandra Regina. Direito e fraternidade: a dignidade humana como fundamento. Revista do Direito. Santa Cruz do Sul, v. 3, n. 53, p. 92-103, set./dez. 2017. p. 96.

${ }^{50}$ BAUMAN, Zigmunt. Identidade: entrevista a Benedetto Vecchi. Tradução de Carlos Alberto Medeiros. Rio de Janeiro: Zahar, 2005, p. 11.

${ }^{51}$ BAUMAN, Zigmunt; DONSKIS, Leonidas. Cegueira moral: a perda da sensibilidade na modernidade líquida. Tradução: Carlos Alberto Medeiros. 1. ed. Rio de Janeiro:Zahar, 2014. p. 53.

52 CASTANHEIRA NEVES, Antonio. Digesta: escritos acerca do direito, do pensamento jurídico, da sua metodologia e outros. Volume $3^{\circ}$. Coimbra Editora. 2008. p. 13
} 
O homem, como pessoa, apenas existirá em um mundo em que haja o reconhecimento como tal pelos que coexistem, sendo que, mesmo o homem livre pode não ser reconhecido como pessoa ${ }^{53}$, sendo necessário, antes de conhecer um homem, reconhecê-lo como tal, e é justamente isso que confere a alguém a qualidade de pessoa.

Os "estranhos", que são vistos como existentes em todas as sociedades, gerando incerteza e medo, são produzidos de forma distinta e própria, sendo que, na modernidade, com promessas de libertação do indivíduo das identidades herdadas, eram aqueles que não se adequavam à visão de ordem existente, vivendo como uma espécie de anomalia que deveria ser retificada ${ }^{54}$.

Entretanto, na realidade, o imigrante deve ser concebido como igual em direitos, mas não em condições, tornando necessário o respeito às diferenças culturais e locais existentes, não sendo razoável crer que uma pessoa proveniente de um país distante, com costumes e culturas distintas, obrigada a se retirar de seu país, possa ser tratada com total paridade para com os nacionais do país que as recebem.

Para que haja um equilíbrio na linha tênue existente entre a necessidade de acolhimento como igual e a cautela com a necessidade de respeito às diferenças, a fraternidade deve ser o caminho escolhido, sendo que, o cidadão fraterno, que receba o refugiado considerando seus sentimentos e sensações, poderá enfim acolhê-lo como outro que necessita de apoio e amparo.

Assim, a alteridade, trabalhada por Emmanuel Lévinas traduz o pensamento de que devemos enxergar ao outro como rosto ${ }^{55}$, e não como estranhos causadores de medo na população. E, somente assim, a partir de uma visão fraterna em que nos coloquemos na posição do outro compreendendo suas condições, será possível não somente receber, mas sim acolher no sentido de compreender o estado de vulnerabilidade existente e as questões que independem da vontade do refugiado que o levam a outro país.

\footnotetext{
53 Ibidem. p. 34

${ }^{54}$ SANTOS, Boaventura de Souza. Pela mão de Alice: o social e o político na pós-modernidade. 14 ed. São Paulo: Cortez, 2013.p. 30

55 Para Lévinas, o ente só pode ser em uma relação em que o invocamos, sendo, enquanto rosto, acessível. LÉVINAS, Emmanuel. Entre nós: ensaios sobre a alteridade. Tradução de Pergentino Pivatto...[et al], 5.ed. Petrópolis, RJ: Vozes, 2010.p. 28.
} 
O estabelecimento de uma relação com o ente implica, além da necessidade e vontade da compreensão, na existência de simpatia ou amor ${ }^{56}$, ressaltando que, quando da compreensão, somente o que escapa do conhecimento é o ente, o que essencialmente demonstra a diferença de quem conhece com relação ao outro. Sobre a relação com o outro, explicita Lévinas:

\begin{abstract}
Ele não entra inteiramente na abertura do ser em que já me encontro como no campo de minha liberdade. Não é a partir do ser em geral que ele vem em meu encontro. Tudo o que dele me vem a partir do ser em geral se oferece por certo à minha compreensão e posse. $\mathrm{O}$ encontro com outrem consiste no fato de que apesar da extensão da minha dominação sobre ele e de sua submissão. Compreendo-o a partir de sua história, meio, hábitos, e o que escapa à minha compreensão é ele, o ente. ${ }^{57}$
\end{abstract}

Deve haver a consciência de que, a identidade do eu não significa a existência de uma condição inalterável, e, no conhecimento verdadeiro, o que ocorre na realidade é que o "eu" deixa que um ser estranho intervenha e entre nessa esfera do conhecimento verdadeiro ${ }^{58}$, de forma que possa conhecer o ser.

Tem-se, portanto, a necessidade de que o outro, refugiado, seja recebido com igualdade de direitos e com consideração às diferenças existentes principalmente com relação à cultura, $\mathrm{o}$ que, de qualquer forma não é capaz de retirar-lhes a condição de seres humanos, razão pela qual a fraternidade, a presença do sentimento, e a solidariedade devem ser as ferramentas utilizadas para evitar a exclusão infundada de quem, na realidade, necessita de acolhimento.

\title{
5. A COMPREENSÃO CONSTITUCIONAL DO OUTRO E A QUESTÃo DO ACOLHIMENTO X EXPURGO
}

Conforme disposto na Declaração de Cartagena de 1984, ampliando o conceito de refugiado, além da questão envolvendo atentado contra direitos, serão considerados os refugiados aqueles que sofrerem perseguição ou temor de abuso de seus direitos e liberdades em razão de violação massiva de direitos humanos ${ }^{59}$, o que justifica o considerável aumento de

\footnotetext{
56 Ibidem. p. 26.

57 Ibidem. p. 30.

58 LÉVINAS, Emmanuel. Descobrindo a existência com Husserle Heidegger. Coleção Pensamento e Filosofia, $\mathrm{n}^{\circ}$ 23. Tradução de Fernanda Oliveira. Lisboa: Instituto Piaget. s.d.p. 227.

59 LUZ, Cícero Krupp da; SIQUEIRA, Estela Cristina Vieira de. A lacuna jurídica do refúgio na era do aquecimento global. In: BAENINGER, Rosana; BÓGUS, Lúcia Machado;MOREIRA, Júlia Bertino [et al.] (org.).
} 
refugiados por todo o mundo, sendo que no ano de 2018 houve mais de 70,8 milhões de deslocamentos forçados no mundo, com um aumento de 2,3 milhões com relação ao ano anterior $^{60}$.

Este elevado número de refugiados também se apresenta na realidade brasileira, e, embora muitos deles cheguem ao país à espera de uma realidade digna e uma recepção adequada, muitos ainda encontram a dificuldade em receber o outro sem discriminação, sendo possível considerar o refúgio como uma das questões mais complexas na comunidade internacional atualmente ${ }^{61}$.

A Constituição da República Federativa do Brasil prevê uma série de garantias referentes aos estrangeiros. Logo no artigo $3^{\circ}$, IV, é identificada como sendo um dos objetivos fundamentais da República Federativa do Brasil, a promoção do bem de todos, sem preconceitos de origem, raça, sexo, cor, idade e quaisquer outras formas de discriminação.

No artigo $4^{\circ}$, são dispostos os princípios que regem as relações internacionais do Brasil, merecendo destaque o inciso II, que se refere à prevalência dos direitos humanos, o inciso VIII, que prevê o repúdio ao terrorismo e ao racismo, e o inciso IX, sobre a cooperação entre os povos para o progresso da humanidade. E, da mesma forma, o artigo Art $5^{\circ}$ prevê a igualdade de todos sem distinções, garantindo tanto aos brasileiros quanto aos estrangeiros residentes no País a inviolabilidade do direito à vida, à liberdade, à igualdade, à segurança e à propriedade, demonstrando, novamente, a preocupação com o estrangeiro.

Nestes primeiros artigos apresentados, é possível observar a preocupação na preservação dos direitos do outro, proveniente de países estrangeiros, dentro do Brasil. Essa

\footnotetext{
Migrações Sul-Sul. 2. ed. Campinas, SP: Núcleo de Estudos de População “Elza Berquó Neop/Unicamp, 2018. p. 691. Disponível em:

https://www.nepo.unicamp.br/publicacoes/livros/migracoes_sul_sul/migracoes_sul_sul.pdf Acesso em: 29/07/2019.

60 Segundo dados da ACNUR, o número de pessoas deslocadas a força deste ano apresenta, novamente, um crescimento recorde. Disponível em:

https://www.acnur.org/portugues/dados-sobre-refugio/ Acesso em 21 de julho de 2019.

61 Direitos humanos e refugiados. Ficha informativa $n^{\circ} 20$. Gabinete de Documentação e Direito Comparado Procuradoria-Geral da República. p. 5 Disponível em:

http://gddc.ministeriopublico.pt/sites/default/files/documentos/pdf/ficha_informativa_20_direitos_refugiados.pdf Acesso em: 25 de julho de 2019.
} 
garantia de direitos pode ser considerada como uma forma de cooperação do país com os demais indivíduos que possam estar inseridos no Brasil, garantindo-lhes, constitucionalmente, direitos.

Para Peter Häberle, a cooperação existente é parte da identidade do Estado Constitucional, e, o paradigma que nomeia Estado Constitucional Cooperativo traz justamente a ideia de entrelaçamento com as relações internacionais, inclusive com relação à solidariedade e aos cidadãos estrangeiros ${ }^{62}$.

São essas relações de cooperação que levam ao necessário convívio entre pessoas com identidades distintas, e, embora existam identidades mais sólidas, nenhuma é imutável, são resultados de processos de identificação ${ }^{63}$ que muitas vezes levam o outro a posições de subordinação. As normas constitucionais são, portanto, parte necessária para que seja estabelecida relação digna e igual entre indivíduos com identidades e culturas diversas.

Por outro lado, é necessário deixar claro que a igualdade não pode ser concebida como algo inerente ao homem, mas sim como algo construído, sendo que, a situação dos refugiados demonstra claramente a impossibilidade de que a igualdade seja identificada com este caráter intrínseco. Nesse sentido, é importante ressaltar o pensamento de Celso Lafer:

\begin{abstract}
De fato, a asserção de que a igualdade é algo inerente à condição humana é mais do que uma abstração destituída de realidade. É uma ilusão facilmente verificável numa situação-limite como a dos refugiados ou dos internados em campos de concentração. Estes se deram conta de que a única dimensão que lhes sobrava era o fato de serem humanos. Pessoas forçadas a viver fora de um mundo comum, vale dizer, excluídas de um repertório compartilhado de significados que uma comunidade política oferece e que a cidadania garante, vêem-se jogadas na sua natural givennes ${ }^{64}$.
\end{abstract}

Sendo assim, embora haja previsão constitucional que garanta ao estrangeiro direitos iguais aos dos brasileiros, na realidade não há uma igualdade que nasça junto com o homem e deva ser garantida apenas por este fato, o que há, é uma construção de direitos que promovam a igualdade, a fim de que principalmente os refugiados, forçados a viver fora de seu país de origem, não sejam excluídos da comunidade em que estão inseridos.

\footnotetext{
62 HÄBERLE, Peter. Estado constitucional cooperativo. Rio de Janeiro: Renovar, 2007. p. 3/6.

${ }^{63}$ SANTOS, Boaventura de Souza. Pela mão de Alice: o social e o político na pós-modernidade. 14 ed. São Paulo: Cortez, 2013.p. 167/168

${ }^{64}$ LAFER, Celso. A reconstrução dos direitos humanos: um diálogo com o pensamento de Hannah Arendt. São Paulo: Companhia das Letras, 1988. p. 150
} 
No mundo globalizado, em que todas as pessoas estão diariamente em movimento, e a distância deixa de ter importância devido à facilidade da mobilidade, há uma consequente expansão da possibilidade de escolhas a serem feitas, e, uma das impossibilidades de escolha neste meio, é a sociedade de nascimento ${ }^{65}$, e, para os que não têm tanta liberdade de escolha de mobilidade, há, muitas vezes, a expulsão de seus lugares de origem.

Um dos grandes saltos passíveis de identificação com relação ao refúgio ocorreu entre os anos de 1975 e 1995, quando o número de refugiados aumentou de 2 milhões para 27 milhões ${ }^{66}$, e é possível observa, anualmente, que os números apresentados pelo Alto Comissariado da ONU apenas aumentam, sendo, neste ano, registrado o número de 70,8 milhões de refugiados ${ }^{67}$ pelo mundo, sendo que, enquanto, por um lado, é possível notar nos países desenvolvidos a receptividade pelos empresários com relação aos refugiados que vêm ao país, e acabam por oferecer mão de obra barata, por outro, nota-se a ansiedade e insegurança causadas pela imprevisão dos "estranhos", que, por sua vez, são diferentes das pessoas que participam do cotidiano e geram expectativas mais precisas nas pessoas. ${ }^{68}$

No primeiro caso, em que se tem a manutenção dos refugiados (estigmatizados) em troca da mão de obra barata, é possível enxergar, também, uma forma de manutenção de poder dos "normais" sob os "estranhos", momento em que a estigmatização é vista como forma de neutralização institucional ${ }^{69}$, diminuindo o valor desses estranhos como pessoas.

Em contrapartida, por muitas vezes o estranho gera medo e insegurança, sendo que, as três razões para o medo ${ }^{70}$ podem ser consideradas como sendo a ignorância, caracterizada pela ausência de conhecimento sobre o que acontecerá posteriormente; a impotência, que é a suspeita de que não há o que ser feito para evitar o que gera o medo; e a terceira é a humilhação, que ocorre quando há a revelação de que não foi feito tudo que poderia ser feito.

\footnotetext{
${ }^{65}$ BAUMAN, Zigmunt. Globalização: as consequências humanas. Tradução: Marcus Penchel. Rio de Janeiro: Jorge Zahar Ed., 1999. p. 93

${ }^{66}$ Ibidem. 96.

${ }^{67}$ Vide nota 19.

${ }^{68}$ BAUMAN, Zigmunt. Estranhos à nossa porta. Tradução de Carlos Alberto Medeiros. 1. ed. Rio de Janeiro: Zahar, 2017. p. 13.

${ }^{69}$ BACILA, Carlos Roberto. Estigmas: um estudo sobre os preconceitos. Rio de Janeiro: Editora Lumen Juris: 2005.p. 29.

70 BAUMAN, Zigmunt; DONSKIS, Leonidas. Cegueira moral: a perda da sensibilidade na modernidade líquida. Tradução: Carlos Alberto Medeiros. 1. ed. Rio de Janeiro:Zahar, 2014. p. 118
} 
E é este medo que leva os imigrantes a uma situação cercada de dificuldades em que, mesmo com esforço para se adaptarem aos novos costumes e cultura do país em que chegam, sofrem com dificuldades que parecem insuperáveis ${ }^{71}$, considerando a ausência de controle com relação ao fato de que são uma minoria étnica.

Nota-se, portanto, que o fenômeno refúgio não se apresenta como algo simples, sendo que o medo gerado quando se refere ao tema carrega certa complexidade. Sobre os problemas que são gerados pela “crise migratória”, importante ressaltar o pensamento de Bauman:

\begin{abstract}
Os problemas gerados pela "crise migratória" atual e exacerbados pelo pânico que o tema provoca pertencem à categoria dos mais complexos e controversos: neles, o imperativo categórico da moral entra em confronto direto com o medo do "grande desconhecido" simbolizado pelas massas de estranhos à nossa porta. $\mathrm{O}$ medo impulsivo gerado pela visão de migrantes portando inescrutáveis perigosentra em luta com o impulso moral estimulado pela visão da miséria humana. ${ }^{72}$
\end{abstract}

Embora exista o medo, é importante lembrar que os fatores que geram essa insegurança não dão o direito à subserviência ou humilhação, visto que hoje há uma quebra da hierarquia de culturas $^{73}$, que passam a ser vistas como horizontais, e não verticais, como um conjunto de culturas e costumes muito diversificados que devem conviver entre si, a fim de que seja possibilitado a um grupo de pessoas, como os refugiados, obter uma identidade.

Essa identidade que lhes falta, considerando a exclusão do espaço em que vivem, leva ao enquadramento dos refugiados à categoria de subclasse ${ }^{74}$, acrescentando o fato de que têm, ainda, a negação da presença física dentro de um determinado território.

Considerando a falta de reconhecimento dos “estranhos", faz-se imprescindível a análise da fraternidade enquanto princípio constitucional explicito, implícito e enquanto opção civilizacional, para a compreensão do fenômeno refúgio, buscando alcançar a conciliação entre as diferenças e as igualdades existentes entre os que batem à porta de outros, e estes outros que os recebem, sendo imprescindível compreensão do mundo concreto em que os refugiados se

\footnotetext{
${ }^{71}$ BAUMAN, Zigmunt. A cultura no mundo líquido moderno. Tradução: Carlos Alberto Medeiros. 1. ed. Rio de Janeiro: Zahar, 2013. p. 41

72 BAUMAN, Zigmunt. Estranhos à nossa porta. Tradução de Carlos Alberto Medeiros. 1. ed. Rio de Janeiro: Zahar, 2017.p. 103.

73 BAUMAN, Zigmunt. A cultura no mundo líquido moderno. Tradução: Carlos Alberto Medeiros. 1. ed. Rio de Janeiro: Zahar, 2013.p. 38

${ }^{74}$ Grupo heterogêneo de pessoas que tiveram sua vida reconhecida socialmente (bios) reduzida à vida puramente animal (zoe). BAUMAN, Zigmunt. Identidade: entrevista a Benedetto Vecchi. Tradução de Carlos Alberto Medeiros. Rio de Janeiro: Zahar, 2005, p.46
} 
encontram para que seja possível não somente receber, mas sim acolher. É o que nós, enquanto civilização, prometemos a nós mesmos. Chega de quebrar promessas!

\section{CONSIDERAÇÕES FINAIS}

Levando em consideração os aspectos mencionados, é possível observar que, mesmo com a vasta previsão constitucional e infraconstitucional acerca do refúgio, não há um completo acolhimento destes pelos países que os recebem, sendo que ainda pode ser notado o preconceito e a discriminação com os "outros", "estranhos" causadores de pânico e medo.

A própria divergência cultural que leva ao medo do "outro", a insegurança de conceber em seu país alguém de origem distinta, com costumes distintos e uma cultura diferente, difere da concepção de cultura moderna, que, segundo Bauman, tem como função criar novas necessidades existentes e atrair clientes, com o mínimo de seletividade o máximo de tolerância possível.

Logo, os estranhos ${ }^{75}$, muitas vezes considerados como sendo os causadores do mal, devido às divergências existentes com os demais, acabam por ser segregados, demonstrando que, ao contrário do que muitos pensam, o mal está na sociedade e se apresenta com maior evidência quando não há uma reação ao sofrimento do outro, que é visto sem sensibilidade e compreensão.

Deve-se levar em contar que não há qualquer saída para a partida dos refugiados, sendo que, caso estes não se retirem de seu país, terão o país retirado de si forçadamente, sendo levados a ocupar lugares desconhecidos e incertos, que muitas das vezes não espelham seus desejos e opção, caso lhes fosse facultada, e tudo isso com o propósito de garantir segurança e proteção.

\footnotetext{
75 Para Bauman, os estranhos são produzidos por todas as sociedades de uma maneira inimitável, e são todos aqueles que não se enquadram no mapa cognitivo, moral ou estético do mundo. BAUMAN, Zigmunt. O mal-estar da pós-modernidade. Tradução: Mauro Gama, Cláudia Martinelli Gama. Revisão técnica: Luiz Carlos Fridman. Rio de Janeiro: Jorge Zahar Ed., 1998. p. 27
} 
Foi possível observar, no presente trabalho, que, em decorrência dessa ausência de sensibilidade para com o outro, há um conflito entre os refugiados e quem os recebe que torna cada vez mais difícil a análise do outro de forma correta, sem que haja segregação dos estrangeiros refugiados no país que lhes recebe.

Para tanto, a fraternidade é a resposta adequada que deve ser adotada com relação ao referido conflito, de forma que, ao enxergar o outro com sensibilidade, como rosto e como pessoa dotada de direitos, será possível atingir uma sociedade mais justa para quem está em busca de proteção por sua situação de refugiado.

Esta concepção é de extrema importância principalmente em se tratando de um país de modernidade tardia, como o Brasil, onde há a necessidade de partilha do pouco que se têm, com pessoas consideradas estranhas e que não participaram da construção da sociedade em questão. Por outro lado, as pessoas que vêm em busca de refúgio são dotadas de direitos assim como todos os outros seres humanos, e, ainda, enfrentam condições de exclusão tanto de seus países de origem quanto dos novos países em que passam a residir.

É possível observar a exclusão com os refugiados em diversos aspectos, como, por exemplo, que mesmo com o grande influxo de refugiados atualmente por todo o mundo, inclusive no Brasil, é possível observar a ausência de divulgação acerca das tragédias decorrentes do refúgio, como o levantamento de muros, mortes e campos de concentração ${ }^{76}$. Por outro lado, essa ocultação não significa que o fenômeno não existe e que não deve ser compreendido, mas tão somente que não é conveniente a exposição de tais questões, tornando a realidade muitas vezes desconhecida por grande parte da população.

Essa ocultação demonstra que, mesmo existindo a previsão na Constituição da República de direitos direcionados aos estrangeiros e, principalmente, com relação aos refugiados, o problema existente persiste, sendo que a exclusão e o preconceito ainda imperam para com os estrangeiros em busca de proteção.

Os direitos constitucionais garantidos aos estrangeiros devem ser preservados e aplicados, mas, por outro lado, não são suficientes para solucionar a exclusão do outro em

\footnotetext{
76 BAUMAN, Zigmunt. Estranhos à nossa porta. Tradução de Carlos Alberto Medeiros. 1. ed. Rio de Janeiro: Zahar, 2017.p.9.
} 
condição de refúgio, visto que envolve aspectos subjetivos e variáveis que não são controladas unicamente pelo texto da constituição vigente no Brasil, tornando necessária a análise do mundo concreto em que a pessoa está inserida para tanto, e, somente assim, visões preconceituosas e equivocadas poderão ser deixadas de lado para dar lugar a um posicionamento ético e fraterno sobre o próximo.

Questões culturais e pessoais são de extrema relevância para compreender não só a igualdade, mas principalmente quais são as diferenças do outro, ressaltando que essas diferenças não são indicativos de ameaça, mas sim de que de fato há uma pluralidade de pessoas com ideais e culturas distintas, que devem, tanto por questões constitucionais quanto fraternas, ser recebidas de forma inclusiva e não exclusiva.

\section{REFERÊNCIAS BIBLIOGRÁFICAS}

ARENDT, Hannah. Origens do totalitarismo. Tradução de Roberto Raposo. São Paulo: Companhia das Letras, 2012.

BAUMAN, Zigmunt. A cultura no mundo líquido moderno. Tradução: Carlos Alberto Medeiros. 1. ed. Rio de Janeiro: Zahar, 2013.

BAUMAN, Zigmunt. Estranhos à nossa porta. Tradução de Carlos Alberto Medeiros. 1. ed. Rio de Janeiro: Zahar, 2017.

BAUMAN, Zigmunt. Globalização: as consequências humanas. Tradução: Marcus Penchel. Rio de Janeiro: Jorge Zahar Ed., 1999.

BAUMAN, Zigmunt. Identidade: entrevista a Benedetto Vecchi. Tradução de Carlos Alberto Medeiros. Rio de Janeiro: Zahar, 2005.

BAUMAN, Zigmunt. O mal-estar da pós-modernidade. Tradução: Mauro Gama, Cláudia Martinelli Gama. Revisão técnica: Luiz Carlos Fridman. Rio de Janeiro: Jorge Zahar Ed., 1998.

BAUMAN, Zigmunt; DONSKIS, Leonidas. Cegueira moral: a perda da sensibilidade na modernidade líquida. Tradução: Carlos Alberto Medeiros. 1. ed. Rio de Janeiro: Zahar, 2014.

CASSIRER, Ernst. A filosofia do iluminismo. Tradução de Álvaro Cabral. Campinas, DP: Editora da UNICAMP, 1992. 
CASTANHEIRA NEVES, Antonio. Digesta: escritos acerca do direito, do pensamento jurídico, da sua metodologia e outros. Volume $3^{\circ}$. Coimbra Editora. 2008.

CUNHA, Paulo Ferreira da. Repensando as fontes do Direito na sociedade da informação. Revista Opinião Jurídica, Fortaleza, v. 14, n. 19, p. 253-280, jan./jun. 2016.

HESPANHA, António Manuel. O caleidoscópio do direito: o direito e a justiça nos dias e no mundo de hoje. $2^{\text {a }}$ ed. Coimbra: Edições Almedina, 2014.

KANT, Immanuel. A paz perpétua e outros opúsculos. Tradução de Artur Morilo. Edições 70: Lisboa, Portugal, s.d.

LEAL, Rogério Gesta. Direitos humanos no Brasil: desafios à democracia. Porto Alegre: Livraria do Advogado, Santa Cruz do Sul, 1997.

LÉVINAS, Emmanuel. Descobrindo a existência com Husserl e Heidegger. Coleção Pensamento e Filosofia, no 23. Tradução de Fernanda Oliveira. Lisboa: Instituto Piaget. s.d.

LÉVINAS, Emmanuel. Entre nós: ensaios sobre a alteridade. Tradução de Pergentino Pivatto...[et al], 5.ed. Petrópolis, RJ: Vozes, 2010.

LUZ, Cícero Krupp da; SIQUEIRA, Estela Cristina Vieira de. A lacuna jurídica do refúgio na era do aquecimento global. In: BAENINGER, Rosana; BÓGUS, Lúcia Machado; MOREIRA, Júlia Bertino [et al.] (org.). Migrações Sul-Sul. 2. ed. Campinas, SP: Núcleo de Estudos de População "Elza Berquó Neop/Unicamp, 2018.

RESTA, Eligio; JABORANDY, Clara Cardoso Machado; MARTINI, Sandra Regina. Direito e fraternidade: a dignidade humana como fundamento. Revista do Direito. Santa Cruz do Sul, v. 3, n. 53, p. 92-103, set./dez. 2017.

SANTOS, Boaventura de Souza. Pela mão de Alice: o social e o político na pós-modernidade. 14 ed. São Paulo: Cortez, 2013.

SARLET, Ingo Wolfgang. A eficáciados Direitos Fundamentais: uma teoria geral dos direitos fundamentais na perspectiva constitucional. 11. ed. rev. atual. Porto Alegre: Livraria do Advogado Editora, 2012.

SILVA FILHO, Edson Vieira; KALLÁS FILHO, Elias. Nós modernos: a crise de efetividade do constitucionalismo contemporâneo à brasileira. In: SIMIONI, Rafael Lazzarotto (org.). Constitucionalismo e democracia 2017: reflexões do programa de pós-graduação em direito da FDSM. São Paulo: Editora Max Limonad, 2017.

Data de Submissão: 13/04/2020

Data de Aceite: $12 / 05 / 2020$ 